\title{
Artificial Intelligence as a Resilient Tool for Fighting Inequalities in the COVID-19 Crisis
}

\author{
Luís Capucha \\ Nuno Nunes \\ Alexandre Calado
}

ISCTE

\section{Abstract}

Can artificial intelligence (AI) be a sustainable way to help solving the Covid19 global problem? What does the way how welfare states, charity organizations and labour markets are dealing with the pandemic crisis tells us about the AI capacity for reducing exposition of underprivileged groups to the desease? It is becoming more and more visible how the new coronavirus pandemic is affecting specifically the most deprived and vulnerable groups, and also the big difference that welfare states and their policies make. What did the pandemic show about the relations between social inequality, welfare state provision and AI? This presentation will discuss the role of AI as a tool for public policies fighting inequalities that were amplified during the Covid19 crisis. It will be analysed how the welfare state, the labour market and social communities are already incorporating AI tools and how this can eventually produce more resilient paths. Accelareted and amplified by the Covid-19, several processes of AI penetration in health, education, healthcare, social security, public administrations, labour and surveillance of citizens, became a subject of public discussion. Artificial intelligence is currently a process of long-term change in health and biotechnologies, long-distance education, teleworking, automation, robotization, consumption behaviours, surveillance and human enhancement. An in-deep analysis of the Portuguese case will support the lessons that can be learnt from AI and its use in public policies in a context of pandemic crisis, leading to a set of political recommendations, to promote its application as a resilient tool to fight inequalities.

Keywords: Covid-19, artificial intelligence, resilience, social inequalities, welfare state, public policies, social communities, capitalism 


\section{Introduction}

SARS CoV 2 pandemic, among the many and very dramatic problems that it has been causing all over the world, and in Europe in particular, has generated a dynamic of extraordinary acceleration of scientific research in the most diverse areas. Naturally, health and life sciences, biology and epidemiology were among the first to be summoned. The behavior of the virus and the impacts it produced were unknown and demanded urgent responses.

However, it soon became apparent that the need for scientific answers could not end there. Social variables, including public health policies, on the one hand, and behavioral patterns and social structures, on the other hand, are equally determinant for the contamination and spread of COVID-19. Understanding these social processes became a central issue on the measures to fight the virus and the effects of the pandemic. Social sciences regained the attention they were losing in the scientific field (as the systematic cuts of research funding programs in recent decades indicates). Durkheim (1966) rose from the ashes of the devaluation of social "things", to affirm the indisputable pertinence of specific knowledge about these same "things". When biology and epidemiology, despite decisive advances, still couldn't combat COVID-19 effectively, it became evident that: (i) the decisions that many governments were taking to retract public health services had to be revised, because they make all the difference; (ii) the timely imposition of political measures such as confinement and closure of institutions and places where the disease could more easily spread was of upmost importance; (iii) the decision of citizens to adopt practices of greater social distancing, use of protective equipment and the adoption of appropriate hygiene habits, could determine the dimension of the impact of the pandemic.

The joint effects of public policies in the field of health, containment policies and radical changes in citizens' habits can be understood as indicators of societies' resilience in the face of this new crisis. This emerging controvertial concept on the political and scientific agenda (Hickman, 2018; Platts-Fowler \& Robinson, 2016) can be pushed and further develop by studying the effects and impacts of this pandemic crisis, which can certainly clarify some of the topics in the debate that were not evident, for example, during the financial, economic and social crisis of 2007/2008 (Blyth, 2013; Geiselberg, 2017; Carmo et al., 2019).

COVID-19 has been an amplifier and an accelerator of another process that was already taking place in modern societies: the "leap" of Artificial Intelligence (AI) from the field of computer science and economic production to domains such as governance and the State's administrative capacity, and the transformation of education, health, social security, work and employment systems (Acemoglu \& Restrepo, 2018; Harari, 2018; Greve, 2019; Hosanagar, 2019). AI is also affecting various aspects of citizens' daily lives. The most recent developments and influence of $\mathrm{AI}$ on society is another dimension that requires examination in the light of what the pandemic has revealed (Bostrom, 2017; Moore et al., 2018; Kearns \& Roth, 2019; 
Hudson, 2019; Zuboff, 2019). What are the negative impacts of AI? Particularly, what is the role of new and super effective mechanisms of citizen control on the deepening of social inequalities that are already so noticeable in neo-liberal capitalist societies and its potential impacts for democracy and freedom? On the other hand, what are the positive impacts of AI on productivity, on the resolution of social problems such as the control of epidemic crises, or on the social participation of excluded groups? These are some topics whose research and reflection have also become urgent ( $O^{\prime} N e i l$, 2016; Costa et al., 2018; Eubanks, 2018; Cotter \& Reisdorf, 2020).

The purpose of this communication is to analyze the interaction established between public health policies, social behaviors and the impacts of $\mathrm{AI}$ in the context of the pandemic crisis of COVID-19.

\section{The Covid-19 pandemic crisis and the fight against it in Portugal}

On March 2, 2020, Covid-19's first positive case was detected in Portugal. The patient was a Portuguese citizen that had just arrived from a visit to Italy. In mid-June, there were about 12,100 people infected with the disease still active, out of a total of 37,336 infected since the beginning of the pandemic (about 0,4\% of the total resident population). 23,212 of those infected people recovered. 1,522 people died, of whom 618 were men over 70 years of age (81.7\% of the total of men's deaths) and 698 were women ( $91.1 \%$ of the total deaths among women). The remaining 502 were awaiting results of further testing. By that period, the lethality rate of Covid-19 was $4.3 \%$ in total and $17.4 \%$ among older people.

The daily number of infections grew between the beginning of March and mid-April at a rhythm of about 1,000 new cases per day (with some fluctuations). Since the beginning of May, it dropped to an interval between 250 and 350 cases per day. The most affected regions were the North and the Centre in the first phase, followed by Lisbon and the Tagus Valley. Alentejo, Algarve, Madeira and Azores have always recorded very low numbers. In the last 15 days the pattern changed, and Lisbon and the Tagus Valley started to contribute between $70 \%$ and $90 \%$ of new daily cases. The number of deaths followed the same pattern, most recently levelling at around 5 per day, after registering around 10 deaths per day in the beginning of May. Hospitalizations numbers follow the same pattern. On June 15, 423 patients $(3.5 \%$ of the total) were hospitalized, of which 71 were in the Intensive Care Units (UCI). The trend of hospitalizations and sick people in the UCI has been decreasing constantly. Throughout the pandemic, the average was 29 hospitalizations per day, currently is much lower.

The main objective announced by the government was keeping infection levels relatively low (between 0.9 and 1 infected by each patient today), in order to avoid the collapse of an excess of stress in health services, and at the same time, create conditions for the resumption of economic activity as soon as the curve of new infections reaches a plateau that can be supported by health services. 
As the first positive case was declared in Portugal in the begging of March, the General Directorate of Health (DGS) declared a Contingency Plan, which included a ban on visits to hospitals and prisons, closure of day centres for the elderly and other "light" measures, under what was called the "mitigation" phase of the impacts of COVID-19. On the 11th of the same month, WHO declared the pandemic situation and the Portuguese health authorities declared that they were and continue to follow the guidelines of the international body. Universities started to close from that date, followed by schools and kindergartens. On March 18, it transitioned to the "national emergency" phase. The emergency plan included confinement measures advised to citizens, incentives to tele-work in the public administration and the private sector, closing companies, establishing conditions for access to lay-off (measures related to access to income were also established later to certain self-employed workers and small employers), and commerce was closed with the exception of establishments selling food, medicines and other essential goods. Going outside home was prohibited, except for those going to work, to assist family members, to make essential purchases, to walk pets, and to exercise. Even in these situations, very strict physical distance rules were implemented. All measures were compiled in norm 97/2020 of the DGS and in Government Ordinance 85-A / 2020, of April 3. The State of Emergency was extended two more times (each time for 15 days), until May 2. However, the deflation that followed is being very gradual: schools were only open to upper secondary students for classes in which they had national exams, commercial spaces were only allowed to resume activity with very restrictive rules, related to the size of commercial surfaces and the type of establishments (for example, gyms only opened in June and until the 15th of this month bars and night clubs, remain closed), the capacity to maintain rules of physical distance remained although more relieved, the use of mask has become mandatory in most public spaces, in which practices and materials for disinfecting spaces and hands must be in place. Rules for the frequency of beaches have been defined, some commercial flights to European and PALOP countries restarted, Shopping Centers opened. These are some of the most emblematic measures tending to partially extend the confination policies. In the most severe period of the epidemic, health services were strongly reinforced, equipment such as ventilators and protection were purchased, and municipalities were adapting different kinds of equipments to became "campaign hospitals" throughout the country (they have never been used).

\section{Crisis Management}

It is worth highlighting some salient aspects of the process. The first concerns the perception of the importance of the role of the State. In the years immediately before the pandemic crisis, public finances experienced a trajectory of sharp reduction in public debt (from 136\% to $117 \%$ of GDP) and mainly of the State deficit, which in 2019 reached for the first time in Portuguese democracy negative values. This was made possible by combining a tripartite logic of reversing the measures of austerity, of resuming economic growth and containing public spending. Thus, there were 
conditions to invest in the health system during the pandemic. On the on other hand, there was not time to recover from the retraction that also had occurred in policies regarding social equipments. Therefore, nursing homes were the context from which almost half of the deaths came out.

In any case, given the refusal of the private health sub-system to meet the needs and the efforts to combating Covid-19 at affordable costs - speculative exploits of acts such as testing were reported - the importance of the public health system was highlighted and the terms of the debate, previously marked by the prevalence of the "single thought" of the superiority of the private over the public management of health equipment, were put into question.

As for policies to support companies and workers in the face of the economic crisis that accompanied and will continue, very harshly, after the pandemic, two widely shared ideas emerged. The first is that the problem of economic recovery (including sustaining support to companies and workers to prevent unemployment) would have to be a European responsibility. The government stated that the future of the European Union would depend on how it operates in this special context. Citizens will look at the EU responses to this crisis as a test of the usefulness of the union. Even countries that diligently updated public accounts, such as Portugal, and managed the crisis more effectively than most of their partners, could not accept the stereotyped discourse of certain countries in Northern and Central Europe about "the South", sometimes brushing up on racism (Capucha et al., 2014).

The second has to do with the importance of proper political crisis management. The government achieved a very long period of national consensus around its measures, largely because they were taken on the advice of technicians, provided at meetings attended by the social partners and opposition parties, as well as the President of the Republic. This also made it possible to make the data provided by the authorities about the pandemic credible, even when they were later revised or adjusted.

\section{The Role of Other Institutional Actors}

Other institutional actors played a decisive role. This was the case of mass media, the Church and several companies. The reaction to the pandemic on the part of the population had a cognitive and reflexive dimension, based on the evidence from peoples' behaviour, mostly following the standards pointed out as correct by institutions of reference and confronting them with the information received.

Intentionally (according to a survey conducted by the National Health School), the majority of the media (televisions, radio, written press) decided to align their speech with authorities in relation to the disclosure of Covid-19 numbers, intending to influence the population to follow the official instructions, and systematically dismantle the disinformation that circulates through social networks. Furthermore, by showing the images of terror that first arrived from Italy and later from Spain, they made a decisive contribution to the absolute success of the families' confinement. If 
on the weekend of March 7 and 8, people still flocked to the beach, these images almost made police action unnecessary, given that the general attitude was one of social distancing at home and scrupulous compliance with the confinement rules.

The Catholic Church reinforced this attitude, by suspending masses in Churches and, mainly, by determining that the pilgrimages and services in Fátima would not take place in the year 2020, lending an enormous symbolic load to the guidelines for confinement. Later, different Churches maintained a leading role, throughout the slow process of ending confinment, by following measures to mantain social distance in the masses and to prevent the risks of contamination during their cult celebrations.

Finally, the initiatives of several companies from different sectors of activity were widely publicized as they, having lost orders and running out of work, at least partially, decided to start reconverting the machines and equipment to produce masks and other protective equipment that was offered to health professionals, civil protection professionals, nursing technicians, etc. Some of them also started to produce for commercialization.

\section{Social Practices, Social Inequalities and Social Resilience}

The same type of solidarity actions carried out by some companies have been followed by citizens, isolated or in groups. These were also widely reported. For example, there were several reports on how in neighbourhoods younger people offered to go shopping for the elderly, and on actions to support homeless people or those subject to other forms of exclusion.

The main reason why the confinement policy was so diligently accepted by the generality of the Portuguese needs further investigation. Was due to fear in the face of Spain and Italy examples? Or it was, as declared by the official political discourse, for reasons of pure civility and awareness of the implication of personal behaviour in the future of the collective? In one way or another the truth is that this behaviour was decisive for the containment of the pandemic to numbers manageable by health services. To the confinement in the housing space, we could add, as a profound change in habits and behaviours, the rapid adaptation to practices such as distance education and the return of "tele -school", the expansion of tele-work (which became common among service workers and public administration), online shopping, the general return to home cooking, among many others.

The set of political, institutional and personal/group dynamics could be called by some authors as the "social resilience" of Portuguese society (Adger, 2000; Rose, 2007). For our part, we just want to mention that, also at the theoretical level, the pandemic crisis brings new elements to the debate on social resilience. First, this designation implies a break with an individualistic view of the concept (Dagdeviren et al, 2020). Resilience appears as something collectively constructed, and not as the product of the "heroic" resistance of individuals fighting against the odds. On the contrary, the existence of resources, institutions and rules, with a key role played by 
the State, was a central and essencial feature of the response to the pandemic. Second, the way Portugal has adapted to the pandemic context tells us nothing about any structural attribute of Portuguese society. Behaviors, initiatives and policies were the historical product of a specific situation, resulting from contingencies and particular contexts. Thus, the thesis that resilience is not an attribute of people, groups or societies, but the result of historically situated processes (Donoghue \& Edminston, 2019), gains more credibility. For these two reasons, resilience does not allow to explain neither the processes nor the social characteristics of people, groups or societies, but only to adjectivate certain processes and certain behaviors.

On the other hand, resilience did not buffer the effect of the structural inequalities in Portuguese society (Mauritti et al., 2016) on the impacts of the pandemic and on its political responses. Initially it appeared that the risk of contamination was random and socially neutral. The first patient diagnosed was a doctor coming from snow holidays, and the least affected regions of the country were the poorest. The main pandemic outbreaks were in northern and central regions, which are not particularly known for poverty. Public figures, including artists and other intellectual workers, were fatally hit.

However, a pattern emerged from an early age: half of the deaths came from nursing homes. That is, from places where the elderly could not protect themselves at an individual level and who became vulnerable due to the weakness of social action policies and the general low quality of social facilities, which the State partly finances, but are managed by third sector organizations. And then, as time progressed and Lisbon and the Tagus Valley became the region where the pandemic still resists, which groups are mostly being affected? Manual workers in certain industrial areas, executive employees in services such as commerce (in particular large retail stores), cleaning workers (a large number of them immigrants living in precarious collective housing), workers who have to use public transport to go to work, usually in precarious jobs, excluded from lay-off measures and that could not afford staying at home. Also particularly affected were people living in poor neighbourhoods and slums. These groups are notably affected by all factors of inequality, ranging from social class to ethnic discrimination (Tilly, 1998; Bihr \& Pfefferkorn, 2008; Therborn, 2013; Savage et al., 2015). It is as if the exclusion of which they are the object had protected them for some time from contact with the virus in a first stage, but inexorably hit them harder on work, on transportation and due to precarious and degraded housing conditions. SARS 2 is not socially neutral and COVID-2 seems to choose its victims among the most vulnerable groups in society.

\section{Dangers and Opportunities brought by Artificial Inteligence}

The public debate about the danger of accentuating social inequalities also arose through other emerging issue: the visibility gained by the AI penetration processes in Portuguese society, similar, at least, to other European societies. AI suddenly appeared to people not as being something for the future, but rather already present. 
In fact, the way the methods of calculating the evolution of the pandemic from the big data treatment and using algorithms to issue orders and make decisions from the processed information were explained; the ability of machines to define the consumption profile of each citizen and promote their match with the products and services made available online; the use of intelligent and precise robots and machines in medical processes; the systematic use of tele-work; the use of distance education; the demonstration of programs to follow the steps of each person, controlling the movements of citizens, all of this started to happen in front of the eyes of all the Portuguese people.

Obviously, it became clear that the inequality between workers and civil servants acquainted with these new realities and the rest, more or less info-excluded citizens, would tend to accentuate. Many low-skilled workers may even lose their jobs or see their working conditions increasingly degraded. Will the jobs created with the 4th generation industry be enough to replace the ones destroyed? Several studies argue that they will, but the experiences of people that are already being replaced gives no reasons to optimistism. The impacts of these trends are already showing to be a danger for democracies in Europe because many of these replaced workers are becoming permeable to political and social radicalism. A populist and nationalist party named Chega, founded in April 2019, elected one parliamentarian for the first time in the general elections of the end of the same year, and is growing on support fast. Polls show it is about to become a third or fourth political force in Portugal.

AI changes the content of work and the industrial relations. Salaries and labour relations are becoming increasingly precarious. This precariousness, as well as the destruction of stable jobs, can jeopardize the financing of systems such as social security, which proved so important for those who benefited from it during the pandemic. Who will pay pensions in the future? Will the State find (and does the State want to) allies strong enough to impose, through taxes and social benefits, a fairer redistribution of the productivity gains allowed by AI? This is a question that was already in the political agenda, but now has emerged as one of the important issues of citizens' concerns. In fact, AI allows for huge productivity gains, but those who are benefiting from these gains are mainly the administrators, the financial system and, at more moderate levels, the more qualified technicians. An increasingly wider gap is separating these priviledged groups from common workers and common citizens, even those who participate in the fabric of AI processes, most of them in a position of being commanded by machines.

On the other hand, new technologies (including some that cannot be considered properly AI, although referring to the same universe of the "new technologies" of communication and information) allow certain social groups, that have been particularly vulnerable to social exclusion, to access new opportunities. People with different types of disabilities are among these groups. We refer to those who communicate through machines, but not in person; those who have difficulty moving 
to work every day; and those that can compensate for physical, sensory and intellectual limitations with the use of technologies. Also, generations that were excluded from school in the past can, through machine-assisted learning processes, overcome their disadvantages and be empowered to participate in the labour market and in society.

The same ambivalence of AI was found in distance education. Hundreds of thousands of children who do not have access to computers or Wi-Fi, neither help at home to follow distance learning and teaching activities, have been heavily penalized by schools closing. But today it has been also demonstrated that, with the proper support for access to equipment and with the action of properly prepared education professionals, distance education overcomes inhibitions and allows to explore potentialities that were invisible before. Especially if distance educational support is used as a complement to classroom teaching.

It is unarguable that AI will have a major impact on productivity in the economy. But oftenly it is not so evident that it will also have similar impacts on the State. Now people can witness how certain machines are capable of executing complicated tasks with enormous precision; how machines process information that allows them to make decisions in super sonic time in different medical acts, which have revealed an unquestionable utility in health care; or the way machines have been able of making (or advising) decisions to control the pandemic. Besides, the administration was able to continue attending different administrative citizens' needs, even when the civil servants were confined at home. How many problems can now be solved without waiting on queues in public services, sometimes to deal with civil servants in a bad mood! Incorruptible machines came into play to solve so many problems, that citizens could perceive that $\mathrm{AI}$ is not just about disadvantages for them. If other crises happen, in the area of health or other, it has been proven that the machine of the State administration does not have to stop.

The use of intelligent machines to follow the movements of ill persons also highlighted the ability that States or, even worse, private interests, have to control and manipulate citizens, which constitutes a real threat to democracy and citizens' freedom. However, we are also witnessing how citizens are using digital communications as a coordination tool for protesting and challenging unfair inequalities. But how much power can they mobilize against the elites who control the new technological assets?

Something that has not been considered in the social and political debate so far is, perhaps, one of the most decisive. It is about taking inequalities to the point of producing a caste of "superhuman" beings (Savulesco \& Bostrom, 2011), endowed with unimaginable capacities and immune to any pandemic. This is what advances in the direction of human enhancement promise, if they continue to be controlled by the interests of a few who can use it to deepen the neo-slavery, that today constitutes one of the most abject products in neo-liberal capitalism on a global scale. Is the absence 
of this major problem a result of a lack of awareness? How many crises are needed to increase the public perception of this threat?

\section{Conclusion}

The future cannot be predicted, but what ordinary Portuguese people became aware in this period is the wonderful and / or diabolical achievements that AI can bring to their present and future lives. Indeed, the Covid-19 pandemic made it visible that AI can interfere, in many ways, in the political, economic and social fabric. These ways are not yet settled. There are divergent trends, some promising other threatening.

The pandemic has shown that AI can deepen inequalities, which today already has reached a level that can hardly be tolerated in the light of human rights, as well as allowing abusive control over citizens. But it can also improve the productivity of the economy, generate wealth, and strengthen the capacity of the State to distribute it fairly. And it can help empower people and make societies more resilient in the face of future crises. In particular, it can help to control the effects of crises and make better decisions and, at the same time, help to improve people's quality of life. It is that kind of resilience that we must stress and endorse.

Covid-19 also showed how the lives of people and social systems can be changed in basic areas such as family life, sociability, education, work, employment and consumption. The impacts of these changes and the way they can be shaped depends on the learning ability of people and, mainly, on the role that the State will play in providing essential responses to people's needs and in the distribution of opportunities, in counterpoint to threats to a very uncertain future.

There is no room in a paper like this to summarize all the policy measures that can be implemented by the State. But some of them can be drafted:

A good part of the measures is to fight against poverty and the exposure of the poor to crises. The first concerns the creation of an income protection sheme to protect both precarious workers, of an amount equivalent to the minimum wage, to be attributed in crisis contexts. This benefit allows confinement of workers who are not covered by lay-off, nor can they work from home, and do not perform essential functions. In the case of workers who perform those functions in precarious working conditions and low incomes, job protection and increased wages should apply, as well as measures for safe access to workplaces. A second measure consists of the launch of a multidimensional program for the qualification of poor and degraded neighborhoods, equipped with sufficient budgetary means to root out the poverty factors resulting from the dynamics of the territory of the neighborhoods themselves;

Launch of a national program based on the principles of the Technological Plan (20052011), which promotes access for the most disadvantaged groups, including children, to computer equipment and technological skills; 
Launch of a national policy to control the quality of social facilities, particularly for the elderly, and financing to the promoting entities in order to allow them to access reasonable quality standards;

Immediately, it will be essential to continue to fund the knowledge that will allow to find effective medical solutions to control the pandemic and reinforce the means available to the National Health System, promoting it's capacity to develop differentiated policies for the most vulnerable segments of the population;

Support the development of AI and its use in the economy and public administration, while simultaneously strengthening the role of the State and civil society in controlling the development of AI systems and mechanisms that can be reflected in the anti-democratic control of citizens. The creation of a High Authority endowed with autonomy and dependent on Parliament would be welcome, with powers to, among other things, monitor the technological and scientific developments that may result in human enhancement.

This is not, of course, a set of policies easy to implement. But if they are not put into force now, when the State is reinforced in its legitimacy, when will they do? Our collective present and future surely demand, at least, that we try.

\section{References}

[1] Acemoglu, D, \& Restrepo, P. (2018). Artificial Intelligence, Automation and Work. National Bureau of Economic Research.

[2] Adger, W. N. (2000). Social and Ecological Resilience: Are They Related? Progress in Human Geography, 24(3), 347-364.

[3] Bihr, A., \& Pfefferkorn, R. (2008). Le Système des Inégalités. La Découverte.

[4] Blyth, M. (2013). Austerity: The history of a dangerous idea. Oxford University Press.

[5] Bostrom, N. (2017). Superintelligence: Paths, Dangers, Strategies. Oxford University Press.

[6] Capucha, L., Estevão, P., Calado, A., \& Capucha, A. (2014). The Role of Stereotyping in Public Legitimation: The Case of the PIGS Label. Comparative Sociology, 13, 482-502.

[7] Carmo, R.M., Nunes, N., \& Ferreira, D. (2019). Social Inequalities and Collective Action in Times of Crisis: The Case of the Lisbon Metropolitan Area. Journal of Civil Society, 15(2), 178-196.

[8] Costa, A.F., Mauritti, R., Martins, S.C., Nunes, N. \& Romão, A.L. (2018). Distributional and Categorial Inequalities in Europe: Structural Configurations. In R.M. Carmo, C. Rio, \& M. Medgyesi (Eds.), Reducing Inequalities: a Challenge for the European Union? (pp.63-74). Palgrave Macmillan.

[9] Cotter, K., \& Reisdorf, B.C. (2020). Algorithm Knowledge Gaps: A New Dimension of (Digital) Inequality. International Journal of Communication, 14, 745-765. 
[10] Dagdeviren H., Capucha, L., Calado, A., Donoghue, M, \& Estêvão, P. (2020). Structural Foundations of Social Resilience. Social Policy and Society, 8(1), 115125.

[11] Donoghue, M. \& Edminston, D. (2019). Gritty citizens? Exploring the logic and limits of resilience in UK social policy in times of socio-material insecurity. Critical Social Policy, 40(1), 7-29.

[12] Durkheim, É. (1966). The Rules of Sociological Method. Free Press.

[13] Eubanks, V. (2018). Automating Inequality. St Martin's Press.

[14] Geiselberg, H. (2017). The Great Recession. Polity Press.

[15] Greve, B. (2019). The Digital Economy and the Future of European Welfare States. International Social Security Review, 72, 79-94.

[16] Harari, Y.N. (2018). 21 Lessons for the 21st Century. Penguin random House.

[17] Hickman, P. (2018). A flawed construct? Understading and unpicking the concept of resilience in the context of economic hardship. Social Policy and Society, 17(3), 409-424.

[18] Hosanagar, K. (2019). A Human's Guide to Machine Intelligence: How Algorithms Are Shaping Our Lives and How We Can Stay in Control. Penguin Random House.

[19] Hudson, J. (2019). The Robot Revolution. Understanding the Social and Ecnomic Impact. Edward Elgar.

[20] Kearns, M. \& Roth, A. (2019). The Ethical Algorithm: The Science of Socially Algorithm Design. Oxford University Press.

[21] Mauritti, R., Martins, S.C., Nunes, N., Romão, A.L, \&. Costa, A.F. (2016). The Structure of European Inequality: A Multidimensional Perspective. Sociologia, Problemas e Práticas, 81, 75-93.

[22] Moore, P., Upchurch, M., \& Whittaker, X. (2018). Humans and Machines at Work. Monotoring, Surveillance and Automation in Contemporary Capitalism. Palgrave Macmillan.

[23] O'Neil, C. (2016). Weapons of Math Destruction: How Big data Increases Inequality and Threatens Democracy. Crown.

[24] Platts-Fowler, D. \& Robinson, D. (2016). Community resilience: a policy tool for local government? Local Government Studies, 42(5), 762-784.

[25] Rose, A. (2007). Economic resilience to natural and man-made disasters: Multidisciplinary origins and contextual dimensions. Environmental Hazards, 7, 383-398.

[26] Savage, M., Cunningham, N., Devine, F., Friedman, S., Laurison, D., McKenzie, L., Miles, A., Snee, H., \& Wakeling, P. (2015). Social Class in $21^{\text {st }}$ Century. Pelican.

[27] Savulesco, J., \& Bostrom, N. (2011). Human Enhancement. Oxford University Press.

[28] Therborn, G. (2013). The Killing Fields of Inequality. Polity Press.

[29] Tilly, C. (1998). Durable Inequality. University of California Press.

[30] Zuboff, S. (2019). The Age of Surveillance Capitalism. Profile Books Ltd.

[31] This work was supported by FCT: UIDB/03126/2020 